Wright State University

CORE Scholar

8-1-1992

\title{
Traps in Semi-insulating InP Studied by Thermally Stimulated Current Spectroscopy
}

\author{
Z. Q. Fang \\ David C. Look \\ Wright State University - Main Campus, david.look@wright.edu
}

J. H. Zhao

Follow this and additional works at: https://corescholar.libraries.wright.edu/physics

Part of the Physics Commons

\section{Repository Citation}

Fang, Z. Q., Look, D. C., \& Zhao, J. H. (1992). Traps in Semi-insulating InP Studied by Thermally Stimulated Current Spectroscopy. Applied Physics Letters, 61 (5), 589-591.

https://corescholar.libraries.wright.edu/physics/40

This Article is brought to you for free and open access by the Physics at CORE Scholar. It has been accepted for inclusion in Physics Faculty Publications by an authorized administrator of CORE Scholar. For more information, please contact library-corescholar@wright.edu. 


\title{
Traps in semi-insulating InP studied by thermally stimulated current spectroscopy
}

\author{
Z.-Q. Fang and D. C. Look \\ Physics Department, Wright State University, Dayton, Ohio 45435 \\ J. H. Zhao \\ Department of Electrical and Computer Engineering, Rutgers University, Piscataway, New Jersey 08855
}

(Received 2 April 1992; accepted for publication 12 May 1992)

\begin{abstract}
Traps in Fe-doped semi-insulating InP samples have been studied by thermally stimulated current spectroscopy with IR $(h v \leqslant 1.12 \mathrm{eV})$ excitation at $81 \mathrm{~K}$. The possible involvement of native defects in determining the compensation mechanisms is suggested based on the observation of other than the usual $0.64 \mathrm{eV}$ Fe-related activation energy for the dark current in one of the four samples supplied from different sources. A metastable behavior of traps in another sample was found and explained by a charge-controlled defect reaction model. Three out of the six traps observed are suggested to be electron traps and one among the other three traps is believed to be a hole trap.
\end{abstract}

Semi-insulating (SI) InP is a very promising material for high-frequency devices and optoelectronic integrated circuits (OEICs). It can be routinely obtained by doping with $\mathrm{Fe}$, which acts as a deep acceptor. Recently, however, nominally undoped SI InP has been obtained by hightemperature annealing under high phosphorus overpressure. ${ }^{1}$ Understanding the defects in this material is very important, since they act as traps and recombination centers, and it has even been inferred that the native phosphorus-antisite defect $\left(P_{I n}\right)$ may play an important role in the compensation mechanism of undoped SI InP. ${ }^{2}$ We have previously used thermally stimulated current (TSC) spectroscopy to study the defects in undoped SI GaAs grown by different techniques, i.e., the liquidencapsulated Czochralski (LEC) and vertical-gradient freeze (VGF) methods. ${ }^{3}$ It was found that the TSC technique with IR $(h v<1.12 \mathrm{eV})$ excitation at $T<90 \mathrm{~K}$ can be used not only to reveal the electron and hole traps, but also to monitor the quenching and enhancement processes of the various traps during IR photocurrent quenching. Many of the GaAs traps are believed to be associated with the transition of EL2, a main native defect $\left(\mathrm{As}_{\mathrm{Ga}}\right.$-related defect) in undoped SI GaAs, from the normal state to its metastable state. ${ }^{4}$

In this letter, we report the application of the TSC technique to $\mathrm{Fe}$-doped SI InP samples. The main results are: (1) the dark current $\left(I_{d}\right)$ for most samples of 250 $\mathrm{K}<T<380 \mathrm{~K}$ is controlled by a deep center with $E_{T}$ $=0.64 \mathrm{eV}$ : (2) unlike the undoped SI GaAs case, no IR photocurrent quenching can be observed; (3) at least six traps are revealed in the range $81 \mathrm{~K}<T<250 \mathrm{~K}$; and (4) in one particular sample a metastable behavior of traps was observed.

The LEC-grown Fe-doped SI InP samples used in the study were provided from four different sources. Hall effect data at $300 \mathrm{~K}$ show that $\rho>10^{7} \Omega \mathrm{cm}$ and $\mu \approx 2500 \mathrm{~cm}^{2} / \mathrm{V}$ $\mathrm{s}$ for the samples. For TSC studies, both In and Au-Ge ohmic contacts were used. Alloying was performed in forming gas at $410^{\circ} \mathrm{C}$ for $5 \mathrm{~min}$ for the In contacts and at $420^{\circ} \mathrm{C}$ for $40 \mathrm{~s}$ for the Au-Ge contacts. The IR light source was provided by a tungsten lamp ( $8 \mathrm{~W}$ ) filtered through a Si wafer, thus allowing photon energies less than $1.12 \mathrm{eV}$. All the currents, i.e., the dark currents $\left(I_{d}\right.$ 's), the photocurrents $\left(I_{\mathrm{ph}}\right.$ 's) at $81 \mathrm{~K}$, and the $I_{\mathrm{tsc}}$ 's were measured under a bias of $20 \mathrm{~V}$. The $I_{d}$ 's were recorded during slow cooling $(0.1 \mathrm{~K} / \mathrm{s})$ at $250 \mathrm{~K}<T<380 \mathrm{~K}$ and the $I_{\mathrm{ph}}$ 's at 81 $\mathrm{K}$ were measured immediately after the IR light illumination. To observe the effect of the illumination time on the TSC spectra, the tested sample was always quickly cooled down from 320 to $81 \mathrm{~K}$ in the dark and then exposed to IR light for various times from $1 \mathrm{~s}$ to $5 \mathrm{~min}$. For consistency, the TSC thermal scan $(81 \mathrm{~K}<T<250 \mathrm{~K})$ with a heating rate of $0.3 \mathrm{~K} / \mathrm{s}$ was always started $30 \mathrm{~s}$ after the termination of the IR light. For comparative purposes, a $1.46 \mathrm{eV}$ light from a GaAs laser diode ( $100 \mathrm{~mW})$ and a white light (without using a Si filter) were used for the carrier excitation at $81 \mathrm{~K}$.

The Arrhenius plots of the $I_{d}$ 's for four samples are shown in Fig. 1. Three samples (Nos. 1, 2, and 3) present a consistent activation energy, i.e., $E_{T}=0.64 \pm 0.01 \mathrm{eV}$, whereas sample No. 4 gives activation energies of $0.59 \mathrm{eV}$ for $T>300 \mathrm{~K}$ and $0.44 \mathrm{eV}$ for $T<300 \mathrm{~K}$. The $0.64 \mathrm{eV}$ center is widely believed to be due to Fe. However, the deep center causing the semi-insulating nature of undoped InP, was determined from the temperature dependence of the carrier concentration to be $0.64 \mathrm{eV}$, too. ${ }^{1}$ The 0.59 and $0.44 \mathrm{eV}$ centers were reported by several authors and attributed to the P-interstitial or In-vacancy, and the Pvacancy in $n$-type LEC InP, respectively. ${ }^{5}$ In the study of defects in nominally undoped SI GaAs, we have found that two different deep centers dominate the dark conductivity, depending on the crystal stoichiometry; i.e., an $0.74 \mathrm{eV}$ center due to EL2 dominates As-rich LEC SI GaAs and an $0.43 \mathrm{eV}$ center controls a number of VGF SI GaAs samples. The fact that there exists more than just the usual $0.64 \mathrm{eV} \mathrm{Fe}$-associated activation energy in some SI InP samples implies the possible involvement of native defects in the compensation mechanism. The photocurrent responses at $81 \mathrm{~K}$ have been measured and no IR photocurrent quenching was observed. An interesting observation is 


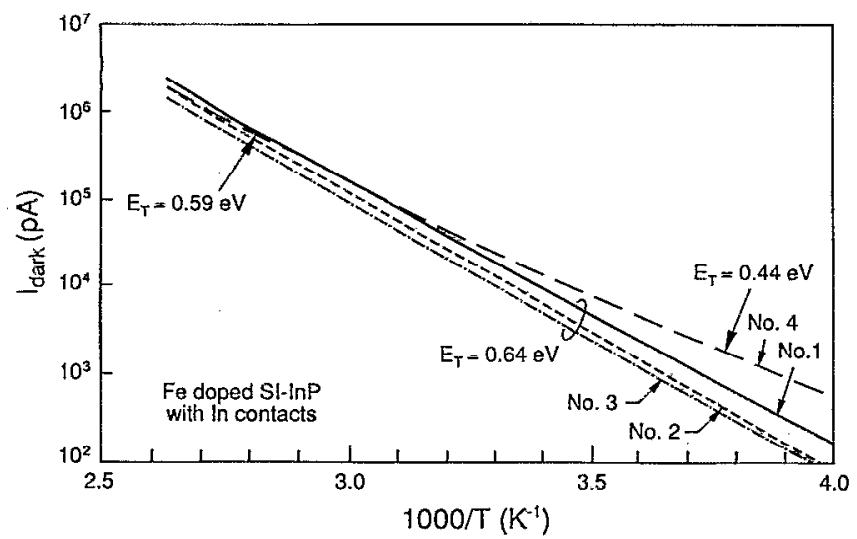

FIG. 1. Arrhenius plots of $I_{\text {dark }}$, showing three different activation energies.

that regardless of the small difference in net photocurrents at $300 \mathrm{~K}$, which vary between 24 and $42 \mathrm{nA}$ for the four samples, Sample No. 1 shows an $I_{\mathrm{ph}}$ nearly two orders of magnitude higher at $81 \mathrm{~K}$ as compared to the others.

The TSC spectra with 5 min IR light illumination for four samples have been measured and at least six TSC peaks are revealed in the range 81 to $250 \mathrm{~K}$. The TSC peaks above $250 \mathrm{~K}$ cannot be observed due to masking by the increasing $I_{d}$ 's. According to the approximate relationship $E_{T}=k T_{m} \ln \left(T_{m}^{4} / \beta\right)$, where $E_{T}$ is the trap depth, $k$ the Boltzmann's constant, $T_{m}$ the TSC peak temperature, and $\beta$ the heating rate for the thermal scan, ${ }^{6}$ the $T_{m}$ 's at a rate of $0.3 \mathrm{~K} / \mathrm{s}$ and the $E_{T}$ 's for the traps are: $T_{b}(168 \mathrm{~K}) 0.32$ $\mathrm{eV}, T_{c}(147 \mathrm{~K}) 0.27 \mathrm{eV}, T_{d}(130 \mathrm{~K}) 0.23 \mathrm{eV}, T_{e}(125 \mathrm{~K})$ $0.22 \mathrm{eV}, T_{f}(99 \mathrm{~K}) 0.17 \mathrm{eV}$, and $T_{g}(88 \mathrm{~K}) 0.15 \mathrm{eV}$.

In Sample No. 1, four traps $\left(T_{b}, T_{c}, T_{e}\right.$, and $\left.T_{f}\right)$ were found, but not trap $T_{d}$. In contrast to the other three samples, when this sample was illuminated with increasing time from $1 \mathrm{~s}$ to $5 \mathrm{~min}$, three TSC peaks $\left(T_{c}, T_{e}\right.$, and $\left.T_{f}\right)$ were decreased in amplitude and the other one $\left(T_{b}\right)$, increased, as shown in Fig. 2(a). In Fig. 2(b) is shown the illumination-time dependence of the TSC spectra using a neighbor sample, but with Au-Ge contacts. These data clearly demonstrate a different variation of the TSC peaks: two of them $\left(T_{c}\right.$ and $\left.T_{e}\right)$ are decreased and the other two $\left(T_{b}\right.$ and $T_{f}$ ), increased. This kind of metastable behavior can be repeated by warming the sample up to $320 \mathrm{~K}$ and then quickly cooling down to $81 \mathrm{~K}$ in the dark. Although effects due to the illumination time can be observed on samples with both types of contacts, there are some differences in the TSC spectral structure: (1) the TSC peaks in the sample with Au-Ge contacts are much lower than those in the sample with In contacts; and (2) the relative peak heights of $T_{e}$ and $T_{f}$ over $T_{b}$ and $T_{c}$ is largely reduced in the former sample. Similar differences were observed in undoped SI GaAs samples, using unannealed $\mathrm{Au}$ or $\mathrm{Au}-\mathrm{Ge}$ contacts on the top and annealed $\left(450^{\circ} \mathrm{C}, 5 \mathrm{~min}\right)$. In contacts on the two ends, and were attributed to differences in the contact properties (Schottky contact versus ohmic contact) and the detected region (near surface versus bulk). ${ }^{3}$ It is possible that the annealing of $40 \mathrm{~s}$ at $420^{\circ} \mathrm{C}$ is not long
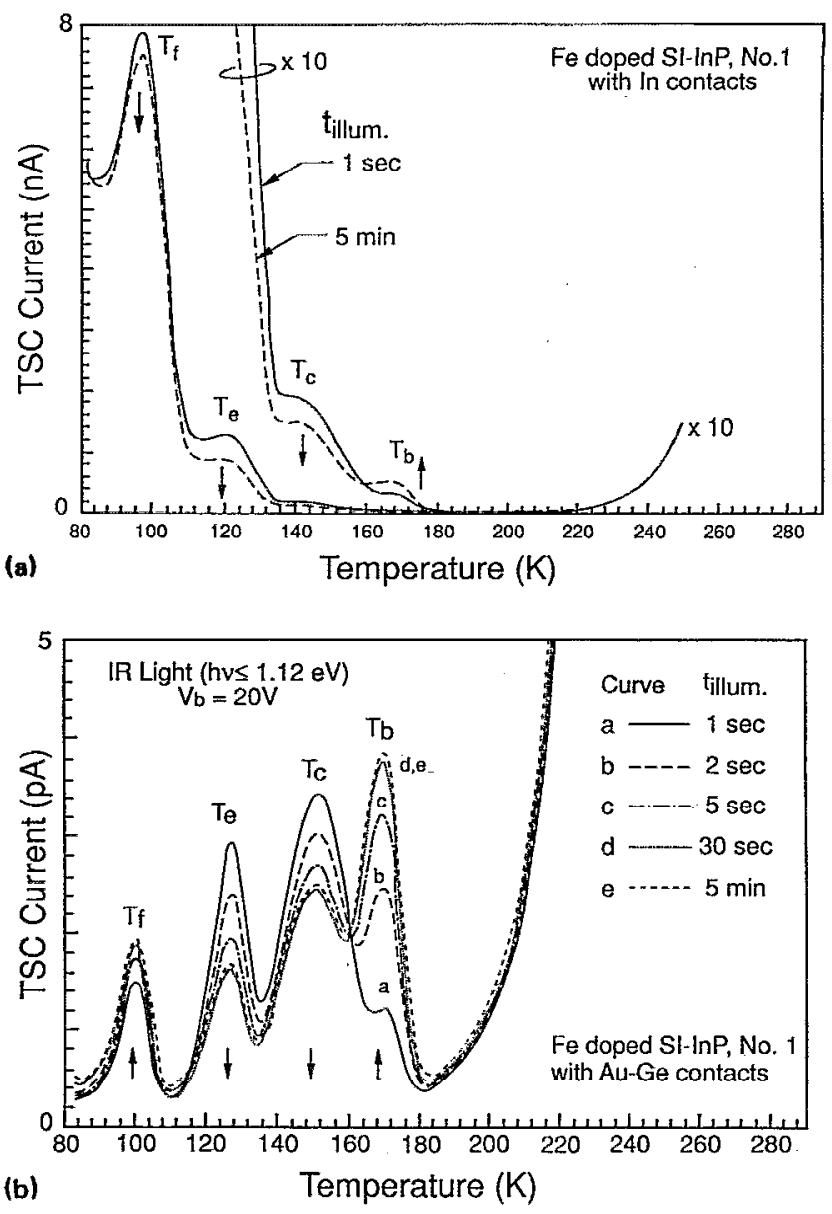

FIG. 2. TSC spectra as a function of the IR light illumination times at 81 $\mathrm{K}$, showing a metastable behavior of traps in sample No. 1 with (a) In contacts and (b) Au-Ge contacts.

enough for Au-Ge on SI InP to form a good ohmic contact.

Several methods can be used to provide information on the trap type: for example, (1) comparison of TSC spectra under positive and negative bias using a sample with a Schottky contact on the top; and (2) Hall effect measurements during the TSC thermal scan. Here we present another method, i.e., comparison of TSC spectra excited with different light sources. Figure 3 shows the TSC spectra excited with IR light $(h v<1.12 \mathrm{eV}), 1.46 \mathrm{eV}$ light, and white light using the sample with $\mathrm{Au}-\mathrm{Ge}$ contacts. It can be seen that $T_{c}, T_{e}$ and $T_{f}$ clearly increase if either white light or $1.46 \mathrm{eV}$ light is used for the excitation at $81 \mathrm{~K}$. From the spectral shapes of the photoionization cross sections for electrons and holes, $\sigma_{n}$ and $\sigma_{p}$, due to $\mathrm{Fe}$ in InP at $77 \mathrm{~K},{ }^{7}$ we know that the hole excitation will dominate the electron excitation when the photon energy $(h v)$ is in the range from 0.78 to $1.12 \mathrm{eV}$ and vice-versa when $h v$ is above $1.27 \mathrm{eV}$. From these arguments, $T_{c}, T_{e}$, and $T_{f}$ can be reasonably assigned to electron traps and $T_{b}$ to a hole trap.

For conventional Fe-doped SI InP, Fe concentrations are in the range of $10^{16} \mathrm{~cm}^{-3}$ for compensating the Si donors $\left(10^{16} \mathrm{~cm}^{-3}\right)$ from horizontal Bridgman polycrystalline starting material. The relative $\mathrm{Fe}$ concentrations in 


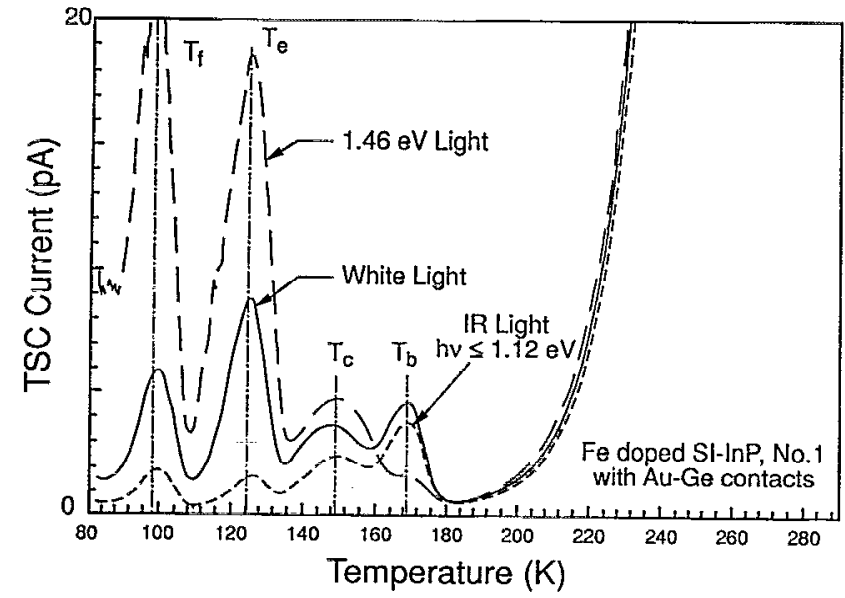

FIG. 3. TSC spectra excited with different light sources at $81 \mathrm{~K}$, showing three electron traps $\left(T_{c}, T_{e}\right.$ and $\left.T_{f}\right)$ and a hole trap $\left(T_{b}\right)$.

the four samples studied were determined by secondary-ion mass spectroscopy (SIMS) to be 3.5, 2.5, 5.0, and 6.2 ppma for samples No. 1, 2, 3, and 4, respectively. Based on the SIMS data, it seems that the big difference in $I_{\mathrm{ph}}$, the TSC spectra, and the metastable behavior between sample No. 1 and the other three samples cannot be explained in terms of the difference in $\mathrm{Fe}$ content. However, the native defects in the samples, such as $P_{\mathrm{In}}, V_{\mathrm{In}}, V_{p}$ and their complexes with each other and with impurities, could be very different, depending on the various crystal-growth conditons. Levinson et al. studied a configurationally bistable defect (MFe center) in lightly Fe-doped $n$-type InP by thermally stimulated capacitance and DLTS. ${ }^{8}$ Depending on the charge state, the authors found that the defect has two atomic configurations, $A$ and $B$, with the transformation $B \rightarrow A$ taking place during the trap filling pulse (or bias off) by electron capture, and the transformation $A \rightarrow B$ taking place between pulses (or bias on) by electron emission or by hole capture. A defect complex, consisting of a multiply charged native defect and an ionized shallow donor, and a kind of electrostatic and lattice-strain-driven defect complex rearrangement mechanism were proposed to explain the transformations. The thermal activation energies of the related electron traps observed in their DLTs spectra were determined to be $0.41 \mathrm{eV}$ for $A_{1}$ and $A_{2}$ in configuration $A$, and 0.24 and $0.35 \mathrm{cV}$ for $B_{1}$ and $B_{2}$, respectively, in configuration $B$. Suppose a similar defect complex exists in our Fe-doped SI InP sample No. 1: then the metastable behavior of the traps observed in the illumination-timedependent TSC spectra can be explained as follows. At the initial stage of IR illumination, hole excitation due to $\mathrm{Fe}^{3+} \rightarrow \mathrm{Fe}^{2+}+h$ is dominant because $p(h v)>n(h v)$ in the IR spectral range, as mentioned above. The capture of holes by the supposed defect complex will cause it to be in configuration $B$, resulting in higher $T_{c}(0.27 \mathrm{eV})$ and $T_{e}(0.22 \mathrm{eV})$, two electron traps similar to $B_{2}$ and $B_{1}$. More electrons will be excited by longer IR illumination through the transition $\mathrm{Fe}^{2+} \rightarrow \mathrm{Fe}^{3+}+e$ and captured by the defect complex, which leads to its configurational transformation from $B$ to $A$, resulting in a decrease of $T_{c}$ and $T_{c}$ and an increase of hole trap $T_{b}$. Warming the sample up to $>300$ $\mathrm{K}$ will cause electron emission from $T_{c}$ and $T_{e}$, resulting in a transformation of the defect complex back into configuration $B$ as observed in the repeated ISC run. Note that we did not observe the electron traps $A_{1}$ and $A_{2}$ due to the masking effects of increasing $I_{d}$ and Levinson et al. did not report the presence of hole trap $T_{b}$ : Obviously, this is a very phenomenological explanation and further studies, especially concerning the behavior of native-defect-related traps in nominally undoped SI InP, are needed.

In conclusion, traps in SI InP from four different sources have been studied by TSC. Six traps have been observed and characterized. It was found that there exists more than just the usual $0.64 \mathrm{eV} \mathrm{Fe}$-associated activation energy for $I_{d}$ in some SI-InP samples which suggests the possible involvement of native defects in determining the compensation. A metastable behavior was found in sample No. 1 and was explained by a charge-controlled defect reaction model. Through the use of different excitation light sources, three of the six observed centers are assigned as electron traps and the other one is suggested to be a hole trap.

We are grateful to Stephen N. Schauer of the US Army ETD Laboratory for SIMS measurements. ZQF was supported by ONR contract N00014-90-J-11847, DCL by US $\Lambda F$ contract F33615-86-C-1062, and JHZ by NSF ECS9114689.

\footnotetext{
${ }^{1}$ K. Kainosho, H. Shimakura, H. Yamamoto, and O. Oda, Appl. Phys. Lett. 59, 932 (1991).

${ }^{2}$ P. Kipfer, D. Hofmann, F. Mosel, G. Muller, A. Schoner, and G. Pensl, in Semi-insulating III-V Materials, edited by A. G. Milnes and C. Miner (Hilger, Bristol, 1990), pp. 11-16.

${ }^{3}$ Z-Q. Fang and D. C. Look, J. Appl. Phys. 69, 8177 (1991).

${ }^{4}$ Z-Q. Fang and D. C. Look, Appl. Phys. Lett. 59, 48 (1991).

${ }^{5}$ C. C. Tin and P. A. Barnes, Appl. Phys. Lett. 53, 1940 (1988).

${ }^{\circ}$ D. C. Look, Semicond. Semimet. 19, 75 (1983).

${ }^{7}$ T. Takanoshashi and K. Nakajima, J. Appl. Phys. 65, 3933 (1989).

${ }^{8}$ M. Levinson, M. Stavola, P. Besomi, and W. A. Bonner, Phys. Rev. B 39, 5817 (1984).
} 